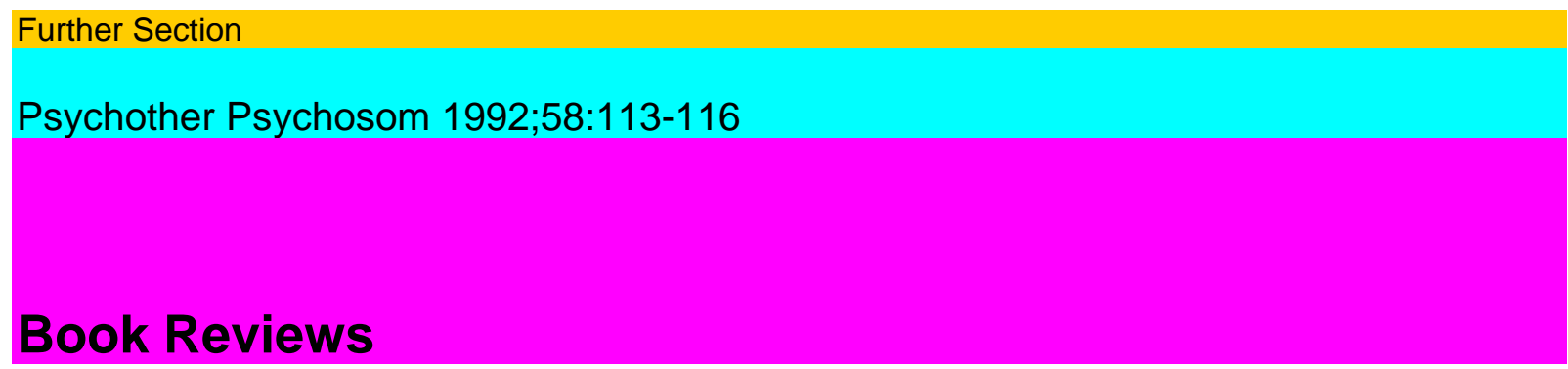

\title{
Fred Salomon
}

Leben und Sterben in der Intensivmedizin, eine Herausforderung an die ärztliche Ethik Wolfgang Pabst, Lengerich 1991. 200 pp.; DM 46.-ISBN 3-92 8057-07-3

Dr. Fred Salomon has completed his studies in theology and medicine. Following his medical habilita-tion in the Center of Surgery, University of Giessen, FRG, Salomon is now Director of the Department of Anesthesiology and Surgical Intensive Medicine, General Hospital, Lemgo, FRG.

With regard to his empirically proved examinations, the author starts from the basic consideration that a responsible intensive medicine is wholeheartedly in need of ethical guiding principles. For this purpose, Salomon arranged well-characterizing research steps in an intensive care unit. These examinations concerned dealing with the patient and his emotional mastering of extremely serious diseases, the dialogue concerning dying and the experience of death as well as the therapeutic decisions. Starting from a fullness of detailed research findings, we present the following key words : the intensive care unit stress factors, to which particularly the nurses are exposed, give important crisis points which are relevant for the purpose of an ethical analysis. Also trainee nurses welcome the medical and nursing training as very satisfying but they distinctly perceive deficiencies with regard to the psychosocial care including feelings of helplessness vis-à-vis dying patients. But on the basis of their original training, the senior nures are insufficiently prepared concerning dealing with dying patients, too. On the basis of exact inquiries, the conclusion may be drawn that, usually, all therapy procedures will not be realized uncritically but the death of the dying patient is decisively admitted, too. The previously treated patients tend to positively assess the terminated intensive therapy on the basis of a retrospective view.

The last third of this book includes a chapter very well worth reading whose contents may be signalized by the following key words: 'image of man and standards of value' as well as 'resulting consequences concerning the intensive medical practice'; furthermore: 'ethics in the dialogue' as well as 'law and ethics', and finally: 'resistance which may be expected vis-à-vis a greater significance concerning ethical reflection in medicine'.

Indeed, Salomon's book does not only present a challenge concerning the medical ethics particularly in intensive medicine but also a basic challenge with regard to the comprehensive introduction of obligatory ethical principles into medicine.

H. Freyberger, Hannover

Peter Halm

Ärztliche Propädeutik -

Gespräch, Anamnese, Interview

Einfiihrung in die anthropologische Medizin -

wissenschaftstheoretische und praktische

Grundlagen 
Springer, Heidelberg 1988. XVIII + 387 pp., 5 fig.; DM 69.-ISBN 3-540-18836-3

Dr. Peter Hahn, internist and psychoanalyst, is Professor and Chairman of General Clinical and Psychosomatic Medicine as well as Director of the Department of Medicine II, University of Heidelberg, FRG. The title of Hahn's book is 'Medical Propaedeutic -

113

Dialogue, Anamnesis, Interview; Introduction to the Anthropological Medicine - Science Theoretical and Practice-Related Foundations'. This book is based on the great tradition of the Heidelberg School in the sense of 'Medical Anthropology' and 'Personal Medicine' which was particularly created by Drs. Victor von Weizsäcker, Ludolf Krehl, Richard Siebeck, and Paul Christian. Starting from his intention to present an introduction to this way of anthropological and psychosomatic thinking, Hahn aims to make evident the necessity with regard to the acquisition of basic knowledge and scientific methods for the purpose of a consideration of the 'constant' and 'connecting' as well as of the 'general' and 'specific' in the human areas. Indeed, this book is suitable to reflect about the controversies between so-called 'orthodox medicine' on the one hand and psychosomatic medicine on the other in respect of the fundamentals of medicine as science. Starting from an unusual approach with regard to a textbook, Halm's specific way of presentation includes a continuous 'text' consisting of the 'pre-instruction' in its contents (in the sense of propaedeutics) on the left page of the book as well as a 'context' on the right page of the book which contains the very personal notes and associations of the author.

Really in his function as a Heidelberg clinician Hahn has full inside experience to put forward a discussion on his own ideas and recollections. Starting from this emotional opening and the connected 'hie et nunc' procedure, the author is able to motivate the reader from his comprehension with regard to the usual and non-usual theory to a new realistic outlook. On the basis of a completely new conception, this book concerns the fundamentals of anthropological psychosomatics which include both general medicine as well as scientific medical practice and personal psy-chotherapeutic experiences. In the view of the reviewer, this book is a very inspiring one.

W. Kämmerer, Hannover

Christa Rohde-Dachser

Expedition in den dunklen Kontinent

Weiblichkeit im Diskurs der Psychoanalyse

Springer, Heidelberg 1991. 340 pp., 17 fig.; DM 38.-ISBN 3-540-53884-4

Dr. Christa Rohde-Dachser is Professor and Chairman of Psychoanalysis at the Institute of Psychoanalysis, University of Frankfurt, FRG. This book entitled

'Expedition into the Dark Continent, Womanhood in the Discourse of Psychoanalysis', is the first volume of a recently founded Springer series entitled 'Psychoanalysis of the Sex

Difference', which is edited by Drs. Rohde-Dachser and Wolfgang Mertens. On the basis of this book series, the two editors hope for a decisive impulse concerning a new far-reaching discussion with regard to the sex topic inside and outside psychoanalysis.

Starting from her book in hand, according to Rohde-Dachser, psychoanalytical arguments have not really agreed with their patriarchate history. On the one hand, this statement would be valid concerning the psychoanalysis of Freud, for in the view of Sig-mund Freud - on the basis of his own confession - the psychology of the woman would always have been a 'dark continent'. On the other hand, the newer theoretical development of psychoanalysis, too, would not make sufficiently evident the dealing with its patriarchate history. On the basis of her following 'expedition' into Freud's 'dark continent', the author achieves the systematical enlightenment of 
the sex ideology in the discourse of psychoanalysis. The question regarding the collective unconscious fantasies by which this discourse is determined represents the center of RohdeDachser's scientific critical examination. This starting point includes not only central categories of psychoanalysis but also the knotting together of psychoanalytical and sociological views. Following this, the author is able to make evident the circular proportion of male and female unconscious areas on the one hand as well as the patriarchal social structure on the other hand. Now, Rohde-Dachser's aim may be clearly perceived, namely to build up an emancipational theory of the sex proportion within psychoanalysis. Finally, the author states that calling into question certain thinking taboos concerning the traditional psychoanalysis on the basis of a feministically oriented ideology, criticims would not be either an effortless or anxiety-free way. Rather, this way would allure compromises at many points or invite change. But according to Rohde-Dachser, she would have been able to withstand this temptation.

This book which is clearly based on the psychoanalytical method bears witness to both the author's greatly brilliant dealing with these complex problems particularly on the basis of very impressive scientific arguments including an unusually intensive and complete research concerning the references as well as a promising beginning with regard to the 'psychoanalysis of the sex difference' Springer series.

H. Freyberger, Hannover

\section{4}

Book Reviews

Karl König

Praxis der psychoanalytischen Therapie

Vandenhoeck \& Ruprecht, Göttingen 1991. 321 pp.; DM 62.-ISBN 3-525-45724-3

Karl König, Reinhard Kreische

Psychotherapeuten und Paare

Vandenhoeck \& Ruprecht, Göttingen 1991. 156 pp.; DM36.-ISBN 3-525-45730-8

Dr. Karl König is both psychoanalyst and Director of the Department of Group Psychotherapy, Center of Psychological Medicine, University of Göttingen, FRG. With regard to this book entitled 'Practice of Psychoanalytic Therapy' König designates the topic 'patient therapy' as the crucial point. Therefore, this book particularly concentrates on the demands of the practicerelated setting. Concerning his theoretic basic positions, König especially fells himself allied to Otto Kernberg. Joseph Sandier and Christa Rohde-Dach-ser. This book consists of three parts. The first part concerns the basic phenomena, namely particularly 'transference', 'unconscious fantasy', 'character and regression' as well as 'transference resistance versus character resistance'. On the basis of the second part, König examines carefully the special features of the classical setting especially with regard to both the patient's free associations and the analyst's specific modality of attention as well as the single phases of the psychoanalytical process from the beginning to the end. Finally, the third part includes the application modalities of psychoanalysis which take place outside the classical setting, namely: group psychotherapy, psychoanalytically oriented individual therapy and the psychoanalytical couple therapy as well as the psychoanalytically oriented therapies in inpatient wards and vis-à-vis psychosomatic patients. On the basis of this didactically written book, König's great experience in dealing with psychoanalytic techniques is signalized. Therefore, this book may be recommended as a greatly successful introduction to the far-reaching topic of psychoanalysis. 
In his second book, entitled 'Psychotherapists and Couples' (together with his close coworker Dr. Rein-hard Kreische), König particularly outlines both the patterns concerning the choice of a partner and the communication between the partners. On the basis of these two modalities, the authors draw diagnostic andpsychodynamic conclusions from the quality of thepatient's drive needs and his ability concerning psychic maturation. Furthermore, starting from their far-reaching experience on an nonempirical basis, Königand Kreische outline the connections between couplerelationship and character structure as well as the regularity concerning the correlations of relationshipneeds, present life features and pathogenic developments. Finally, the authors bring in relation to thesepatient-oriented processes the personality structures ofthe therapists. This book which started from König'sand Kreische's original hypotheses may be stimulatingto all the colleagues who are dealing with coupletherapy. H. Freyberger, Hannover

Robert Kellner

Psychosomatic Syndromes and Somatic

Symptoms

American Psychiatric Press, Washington 1991. 260 pp.; \$ 32.00 ISBN 0-88048-110-2

A young medical graduate once asked me how come disorders that are so widespread in medical practice, the 'functional medical disorders', find so little room in medical textbooks. There is no easy answer to this question. Maybe it is because these disorders have strong psychological components that are believed to lie marginal to the field of medical science. Maybe it is because they are ill-defined illnesses for which little research evidence is available. This book calls such views into question. It is a scholarly review of clinical and research aspects on various psychosomatic syndromes: fibromyalgia, fibrositis, chronic fatigue, glo-bus and fear of chocking, dysphagia and esophageal motility disorders, nonulcer dyspepsia, irritable bowel syndrome, urethral syndrome, hyperventilation and aerophagia, chronic pain syndromes. These disorders are discussed in the first part of the book with exceptional clarity. The second part is devoted to a description of the mechanisms of bodily complaints, and includes discussions of somatization, hysteria and deception.

This book can probably be seen as the companion to standard textbooks of medicine, such as Harrison's Principles of Internal Medicine, in the sense that it deals with very important clinical issues which are completely overlooked by these textbooks. Take fibro115

myalgia, for example. In the latest (12th) edition of Harrison's there are 14 lines about this disorder. Yet its prevalence is $15-20 \%$ of patients in a rheumatology clinic and 6-11 \% in a general medical clinic. Are those 14 lines sufficient for clinicians working in such clinics? Do they really summarize what it is important to know about these patients? The answer is, obviously not. Similar considerations apply to the other medical disorders described in this volume.

Robert Kellner has already written a volume on hypochondriasis [1] which has become the standard reference in the field. It is not difficult to recognize in Psychosomatic Syndromes and Somatic Symptoms the

signs of another 'classic' that will be quoted for a long time. It is strongly recommended to any physician working in clinical practice, regardless of his/her speciality or field (whether general medicine or psychiatry, rheumatology or gastroenterology). It teaches us how to deal with these patients both in the light of research evidence and with an understanding attitude.

G.A. Fava, Bologna 
Reference 1 Kellner. R: Somatization and Hypochondriasis. New York, Praeger, 1986.

1. 116

Book Reviews 